\title{
Professionals as responders: variations in and effects of response rates to questionnaires, 1961-77
}

\author{
ANN CARTWRIGHT
}

British Medical fournal, 1978, 2, 1419-1421

A basic feature of the work of the Institute for Social Studies in Medical Care (formerly the Medical Care Research Unit of the Institute of Community Studies) is that, in its studies of the social aspects of health care, viewpoints of both patients and professionals are considered. Over the past 16 years we have approached 19 samples of professional groups and asked them to participate in our surveys by answering some questions. Their response rates have varied from $56 \%$ to $99 \%$. This paper considers two questions: what factors influence response rates and in what ways the responding professionals may be unrepresentative.

\section{Factors influencing response rates}

Table I summarises the response rates to the various studies. Variable factors that seem to have influenced response rates are: the type of professional (doctors or nurses, general practitioners or consultants); the type of approach (interview or postal questionnaire); the length of the questionnaire; the sponsoring body; and the subject of the study. Response rates also seem to have declined with time. Before discussing these factors, I shall discuss ways in which our methods of approach have remained the same.

Institute for Social Studies in Medical Care, London NW3 2SB

ANN CARTWRIGHT, BSC, PHD, director

Our initial letter for both interview and postal studies is on headed paper from the institute and is mimeographed. The name of the recipient is written or typed in, and the letters have generally been signed individually. Points that are made in the letter are: the aim of the study; how we got the recipient's name; information is treated confidentially and is not passed to anyone outside the institute, and in any reports or publications individuals or particular hospitals cannot be identified.

Envelopes have sometimes been handwritten and sometimes typed. We have not done a study about this. We have always used stamps rather than a franking machine.

Postal questionnaires are sent with a serial number that enables us to identify who has responded and to link replies with any other information we have about the individuals.

Reminders-Two reminders are normally sent in postal studies, but in one study $^{1}$ we used one postal and one telephone reminder. Additional questionnaires and prepaid envelopes have been included with all second reminders, and latterly with first reminders as well. One of the reminders has usually been written and signed by a member of the profession approached who had some ties with the institute.

TYPE OF PROFESSIONAL

Our response from doctors has varied from $56 \%$ to $86 \%$, while for nurses (health visitors, midwives, and district nurses) it has never been below $78 \%$ of those in the sample and has been as high as $99 \%$. With nurses the main problem has been getting lists of people working in our sample of areas or hospitals. Once we had the lists our success rate has always been over $90 \%$ (table I). Nurses may be more likely to respond than doctors because they are less often asked to take part in such studies. But the exceptionally high response from those approached suggests that if the medical officer or nursing officer gave us a list of the people we wanted to see the nurses thought that this

TABLE I-Response from professionals to studies carried out by the Institute for Social Studies in Medical Care

\begin{tabular}{|c|c|c|c|c|c|}
\hline Study & Professional group & Year & Approach & Response rate (\%) & No in initial sample \\
\hline 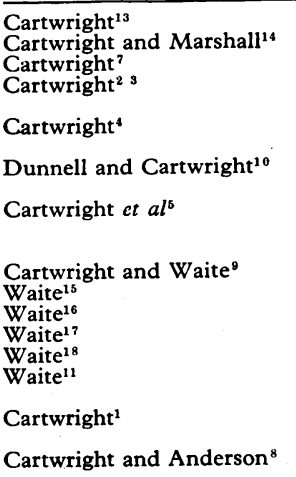 & $\begin{array}{l}\text { General practitioners } \\
\text { General practitioners } \\
\text { General practitioners } \\
\text { General practitioners } \\
\text { General practitioners } \\
\text { Health visitors } \\
\text { General practitioners } \\
\text { General practitioners } \\
\text { District nurses } \\
\text { Health visitors } \\
\text { General practitioners } \\
\text { Health visitors } \\
\text { Domiciliary midwives } \\
\text { Consultant general surgeons and urologists } \\
\text { Consultant psychiatrists } \\
\text { Consultant gynaecologists } \\
\text { Hospital-based midwives } \\
\text { Consultant obstetricians } \\
\text { General practitioners }\end{array}$ & $\begin{array}{l}1961 \\
1963 \\
1964 \\
1967-8 \\
1967-8 \\
1967-8 \\
1969 \\
1969 \\
1969 \\
1969 \\
1970-1 \\
1970-1 \\
1970-1 \\
1971 \\
1971 \\
1971 \\
1975 \\
1975 \\
1977\end{array}$ & $\begin{array}{l}\text { Interview } \\
\text { Interview } \\
\text { Postal } \\
\text { Postal } \\
\text { Interview } \\
\text { Interview } \\
\text { Postal } \\
\text { Interview } \\
\text { Postal } \\
\text { Interview } \\
\text { Interview } \\
\text { Postal } \\
\text { Interview } \\
\text { Interview } \\
\text { Postal } \\
\text { Postal } \\
\text { Postal } \\
\text { Interview } \\
\text { Postal } \\
\text { Postal }\end{array}$ & $\begin{array}{l}86 \\
81 \\
76 \\
72 \\
76 \\
98^{*} \\
78 \dagger \\
56 \\
84 \\
77 \\
95 \\
99 \\
68 \\
98 \\
97 \\
74 \\
82 \\
83 \\
93 * \\
81+ \\
58 \\
67\end{array}$ & $\begin{array}{r}144 \\
195 \\
552 \\
1917 \\
702 \\
234 \\
294 \\
581 \\
411 \\
532 \\
76 \\
889 \\
773 \\
527 \\
553 \\
476 \\
399 \\
418 \\
480 \\
649 \\
543\end{array}$ \\
\hline
\end{tabular}

*Indicates response rate after nurses had been identified from official lists of those working in sample area or hospital (see text).

Indicates response rate after nurses had b 
was official sanction for the study. Among the different types of doctors, our response rate from general practitioners has varied from $56 \%$ to $86 \%$, and from consultants the range has been similar- $58 \%$ to $83 \%$.

\section{INTERVIEW OR POSTAL INQUIRY}

We have twice tried an approach by interview and by post to comparable samples of general practitioners on similar topics. In both instances the response was insignificantly higher among those in the interview group $\left(76 \%\right.$ against $72 \%$ in the studies of family planning ${ }^{2-4}$ and $84 \%$ compared with $77 \%$ in the study of Life before Death ${ }^{5}$ ). Together the results of the two studies suggest a marginally better response to the interviews, but the difference is small and the cost of interviews so much greater that recently we have used a postal approach to general practitioners. On the other hand, all our studies of health visitors, district nurses, and midwives have been done by interview. This was partly because we could usually make appointments and interview them relatively economically at their place of work, but also because we thought that a postal approach to their clinic or hospital base (the only address we had) might encourage discussion and collaboration and lead to a concensus response rather than individual ones.

\section{LENGTH OF QUESTIONNAIRE AND SPONSORING BODY}

In 1967 we did an experiment in collaboration with the Medical Care Research Unit at Sheffield University. The general practitioners in Sheffield were divided into four groups in a $2 \times 2$ design. Two were sent a short, single-page questionnaire, two a longer four-page one. For two groups the questionnaires were sent from Sheffield University and for the other two from the Institute of Community Studies in London. Results (table II) showed that both the length of the questionnaire and the sponsoring organisation affected the response rates as expected. ${ }^{6}$

TABLE II-Variation in response rate from local general practitioners, according to length of questionnaire and sponsoring organisation. Figures are numbers (\%) of responders

\begin{tabular}{|c|c|c|c|}
\hline \multirow{2}{*}{ Organisation } & \multicolumn{2}{|c|}{ Questionnaire } & \multirow{2}{*}{ Total } \\
\hline & Short & Long & \\
\hline $\begin{array}{l}\text { Sheffield University } \ldots \text {. } \\
\text { Institute of Community Studies, London } \ldots\end{array}$ & $\begin{array}{l}57(96) \\
58(83)\end{array}$ & $\begin{array}{l}59(78) \\
58(67)\end{array}$ & $\begin{array}{l}116(87) \\
116(75)\end{array}$ \\
\hline Total & $115(90)$ & $117(73)$ & $232(81)$ \\
\hline
\end{tabular}

\section{SUBJECT MATTER AND TIME TRENDS}

In $1964^{7}$ and again in $1977^{\circ}$ we did a study of general practice and of general practitioners' views and experiences of their work; and in $1967-8^{2} 3$ and again in $1970^{9}$ we surveyed general practitioners' attitudes and practices in relation to contraception. We were covering comparable samples of doctors on the different occasions. Response rates (figure) seem to have fallen with time. But the subject of the study seems to have had a greater effect on the response rate than the difference in time. This is suggested by results of two other studies carried out in 1969: one asking about the care of the dying had a relatively high response rate of $77 \%$; the other on prescribing and self-medication a comparatively low one of $56 \% .^{10}$

General practitioners probably see prescribing as a potentially more threatening subject than terminal care. The drop in the response rate to our two general-practice studies is all the more notable in that we had the backing of the General Medical Services Committee in 1977, while in 1964 we did not. So the fall in response rates has to be seen in the context of increasing support and recognition by professional bodies. The two studies in which we have approached consultants in obstetrics and gynaecology had very differing response rates. In 1971,11332 out of $399(83 \%)$ co-operated in a study of birth control services, while in 1975 only 379 out of $649(58 \%)$ responded to a study of induction. ${ }^{1}$ Both time and subject matter probably contributed to this difference.

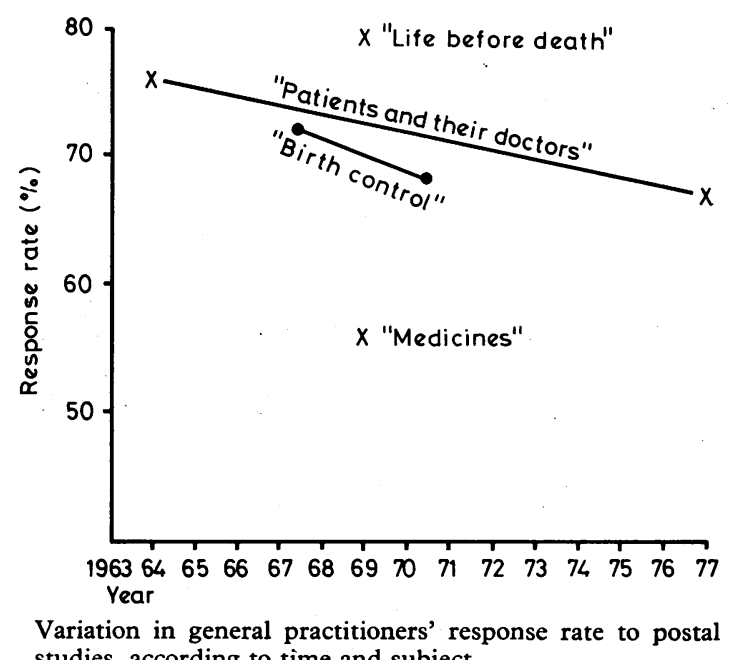

studies, according to time and subject.

\section{How representative are the responders?}

Data about those who do not respond are usually limited to basic information from records such as date of birth (or year of qualification), sex, qualifications, type of area or appointment and, for general practitioners, list size and number of partners. Generally we have found that younger doctors are more likely to respond than older ones. For instance, in Patients and Their Doctors ${ }^{7}$ the response rate of general practitioners rose from $67 \%$ of those who qualified before 1935 to $88 \%$ of those qualifying in 1955 or later; while in Parents and Family Planning Services ${ }^{4}$ it was $63 \%$ among those aged 65 or more, rising to $90 \%$ of those who were under 30 . Nevertheless, no such variation in response with age occurred in Life Before Death, ${ }^{5}$ so possibly older doctors found this subject more appealing than younger ones. Response rates from men and women doctors have been generally similar, although $87 \%$ of women general practitioners responded in Parents and Family Planning Services ${ }^{4}$ compared with only $74 \%$ of the men. Again, this may reflect a greater interest in the subject. Another general finding was a rather higher response from the better qualified or-among consultants-from those who held university appointments rather than NHS ones. In general practice, single-handed doctors have been less likely to participate than those working with others. Hence the bias is apparently towards the less isolated and more "with-it" doctors. Nevertheless, the characteristics we can study in this way are few, but fairly basic.

A potentially more sensitive indication of bias comes from the studies in which we have linked data from patients and professionals. We could do this only for general practitioners, but in several studies we could compare the patients' views and attitudes towards their general practitioners for doctors who participated and for those who did not. In these studies we often had the views of more than one patient about the same doctor, and the sample base was therefore patients' doctors. Results for the various studies are summarised below.

\section{Parents and Family Planning Services ${ }^{4}$}

Mothers who had doctors who did not collaborate were no less likely than other mothers to have discussed birth control with their present general practitioner, and they were about as likely to regard him as their most helpful source of advice and information. But when they were asked who they thought they would find it easiest to talk to about family planning (their own doctor or the health visitor) mothers with doctors who collaborated were more likely to say their own doctor than mothers whose doctors did not take part $(59 \%$ compared with $50 \%$ ). Variations in the proportion of mothers who thought that their general practitioner had enough time to talk about family planning ( $47 \%$ for the collaborators, $42 \%$ of the noncollaborators) and differences in the proportions of mothers currently taking the pill $(21 \%$ and $16 \%)$ were not statistically significant $(0 \cdot 10>\mathbf{P}>0.05)$. But when mothers had discussed birth control with their doctors $26 \%$ of the collaborating doctors had discussed two or more methods, while $19 \%$ of the non-collaborators had done this. 
Medicine Takers, Prescribers, and Hoarders ${ }^{10}$

Eighty-five per cent of the adults whose doctor completed the questionnaire thought that their doctor had enough time to listen and do everything necessary for patients; fewer of those with doctors who did not reply $(76 \%)$ described their general practitioner in those terms. A possible explanation is that the doctors who did not collaborate were busier than the others, so one reason for noncollaboration was lack of time. Adults were also asked whether they would discuss a personal problem with their doctor. Forty-four per cent of those whose doctor replied said they would, compared with $37 \%$ of the others. Nevertheless, the patients of those doctors who did not collaborate had consulted their doctors a similar number of times during the previous year to those people whose doctors completed the questionnaire. More importantly for the study, the proportions of people who had taken medicine, either prescribed or non-prescribed, did not differ.

\section{Life Before Death ${ }^{5}$}

There was no difference in the place of death of patients whose doctors participated in the study and those who did not, but patients of doctors who did not collaborate were less likely to have had 10 or more home visits in the year before they died (35\% compared with $44 \%$ of patients whose doctors did take part) and they were less likely to have been visited by a district nurse (27\% compared with $39 \%)$. Relatives more often thought that the doctor did not have time to discuss things when he failed to reply to the questionnaire $(24 \%$ compared with $14 \%$ ). A higher proportion said that they had known what was wrong with their dead relative when the doctor co-operated $(51 \%)$ than when he did not $(38 \%)$, and more of them said that they had got most of their information from their dead relative's general practitioner ( $48 \%$ compared with $37 \%$ ). These findings suggest that the general practitioners who responded may have had a somewhat closer relationship with their patients and their patients' families than those who did not.

\section{Patients and Their Doctors in $1977^{\circ}$}

Unlike the study of medicines, patients' assessments of doctors who did and did not respond did not differ about their listening or taking time. Nor did the two groups differ in their assessments of whether they would discuss a personal problem with their doctor. The two groups seemed to be equally satisfied or dissatisfied with their care and equally critical or uncritical of their doctors. If the patients saw their relationship with their doctor as businesslike, the doctor was more likely to respond than if the patient described it as friendly (70\% compared with $60 \%$ ). Perhaps the businesslike doctors are more systematic.

\section{Discussion}

On the whole the comparisons between the professionals who participated in our studies and those who did not are reassuring because they do not indicate any large bias. The same conclusion was reached in an American study of physicians who did and did not respond to a postal questionnaire, ${ }^{12}$ even though the response rates in our studies sometimes dropped to a level that they would regard as unacceptably low. In practice the extent of the biases did not seem to be strongly related to the response rate: the number and direction of identified biases was at least as great in the study of terminal care, in which the response rate was $79 \%$, as in the study of medicines, in which it was $56 \%$.

Probably the most worrying finding is the drop in response from doctors over time. One possible explanation may be an increasing apathy or antagonism towards health-service research associated with government. This would be ironic, since the aim of much research is to ensure that bureaucrats are aware of the views of the people concerned. Alternatively, doctors may have become the targets for an increasing number of studies, and some may have responded by rejecting all such appeals, others by responding selectively to those that they find particularly interesting, and others by demanding the type of reward that is sometimes offered by pharmaceutical firms when they do such studies. Some evidence suggested that certain subjects were seen as more threatening than others, and also that some topics appealed to certain types of doctors. Health visitors, midwives, and district nurses, on the otherhand, seem to be asked about their professional views and experiences relatively infrequently. Several of them said that they were glad that we were taking notice of their point of view, and this feeling, together with their inclination to accept what their seniors had approved, probably contributed to their relatively high rate of response.

The direction of the biases that were identified among the non-responding doctors suggested that they were older, more isolated, less well-qualified, and rather less likely to be regarded as helpful and sympathetic by their patients. They also seemed to have a less positive attitude to research.

I thank Abe Adelstein, Robert Anderson, Valerie Beral, Charlie Cannell, Karen Dunnell, Wendy Farrant, Rosalind Lam, Jean Martin, Louis Moss, Alison Venning, Marjorie Waite, and Audrey Ward for helpful comments.

\section{References}

1 Cartwright, A, The Dignity of Labour? In press.

2 Cartwright, A, Medical Officer, 1968, 120, 43.

3 Cartwright, A, Studies in Family Planning, 1968, 32, 10.

4 Cartwright, A, Parents and Family Planning Services. London, Routledge and Kegan Paul, 1970

5 Cartwright, A, Hockey, L, and Anderson, J L, Life before Death. London, Routledge and Kegan Paul, 1973.

${ }^{6}$ Cartwright, A, and Ward, A, British Fournal of Preventive and Social Medicine, 1968, 22, 199.

${ }^{7}$ Cartwright, A, Patients and Their Doctors. London, Routledge and Kegan Paul, 1967.

${ }^{8}$ Cartwright, A, and Anderson, R, Patients and Their Doctors in 1977. Evidence to the Royal Commission on the National Health Service, 1978.

${ }^{9}$ Cartwright, A, and Waite, M, Fournal of the Royal College of General Practitioners, 1972, suppl No 2, p 22.

${ }^{10}$ Dunnell, K, and Cartwright, A, Medicine. Takers, Prescribers and Hoarders. London, Routledge and Kegan Paul, 1972.

11 Waite, M, Consultant Gynaecologists and Birth Control. London, The Birth Control Trust, 1974.

12 Gough, H G, and Hall, W B, fournal of Applied Psychology, 1977, 62, 777.

13 Cartwright, A, Human Relations and Hospital Care. London, Routledge and Kegan Paul, 1964.

14 Cartwright, A, and Marshall, R, Medical Care, 1965, 3, 69.

15 Waite, M, Nursing Times, 12 October 1972.

16 Waite, M, Nursing Times, 14 December 1972.

17 Waite, M, British Medical fournal, 1973, 2, 629

18 Waite, M, Journal of Psychological Medicine, 1974, 4, 74

(Accepted 18 August 1978)

\section{What is the nature of the blood-brain barrier?}

It has been known for many years that there are substances that penetrate into the central nervous system either very slowly, or not at all, but which readily enter other tissues. The exact site of this bloodbrain barrier is still debated, but is probably due to the tight junctions between endothelial cells of brain capillaries. The passage of substances across the blood-brain barrier is largely determined by their facility to cross (and therefore dissolve in) the lipid membranes of the surrounding endothelial cells. Lipid-soluble drugs therefore penetrate into the central nervous system very readily, while most lipid insoluble ones do not. Few substances (such as levodopa), however, cross by active transport. In meningitis, encephalitis, and uraemia there is some degree of "breakdown" of the blood-brain barrier, which allows penicillin to cross into the central nervous system.

\section{Correction}

\section{Brucellosis}

In the Any Question? on brucellae and Mycobacterium tuberculosis (4 November, $\mathrm{p} 1281$ ) the co-trimoxazole dosage should have been given as 10 and $50 \mathrm{mg} / \mathrm{kg}$ daily. 